\title{
Size, Entropy, and Density: What is the Difference That Makes the Difference Between Small and Large Real-World Assortments?
}

\author{
Barbara Fasolo \\ London School of Economics and Political Science \\ Ralph Hertwig \\ University of Basel, Switzerland \\ Michaela Huber \\ University of Colorado at Boulder \\ Mark Ludwig \\ London School of Economics and Political Science
}

\begin{abstract}
Consumer research has shown the downsides of offering consumers too much choice and is now starting to explore moderators of the effect of assortment size on consumer decisions. Building on previous studies, this research examines two side effects of tyranny of choice in the marketplace: high assortment entropy and high density of attribute values. We analyze two supermarkets-one offering small, the other large assortments-to examine how size, entropy, and density relate in the marketplace. We find that larger supermarket assortments come with higher density and higher entropy. Simulations of various choice strategies in these marketplace assortments reveal that making selections from large high-density and high-entropy
\end{abstract}


According to the New York Times, the average size of U.S. grocery stores has been growing steadily for 20 years, with some stores now larger than a football field and carrying as many as 60,000 items (September 10, 2008). The rationale behind this growth is that customers want choice and variety. Large assortments render it more likely that all types of consumers will find something they need or desire. However, research in consumer and social psychology has recently demonstrated that when customers do not have an ideal product in mind-not an uncommon situation-they have more difficulty choosing from large assortments than from small assortments (Iyengar \& Lepper, 2000; Schwartz, 2000, 2004; Chernev, 2003a, 2003b; Shah \& Wolford, 2007). Large assortments appear to overload customers with information, rendering it more difficult for people to identify the product they prefer. In other words, a wealth of goods exacts the risks of undesirable psychological and economic costs such as long search times, dissatisfaction, regret or, worse yet, choice deferral altogether. Perhaps because of its implications for people's happiness and the prevailing Weltanschauung that espouses self-determination through choice, recent research on the dire consequences of abundant choice has been heatedly and publicly debated in the media, on the Internet, and on numerous blogs.

Despite the current fascination with the topic, the finding itself-that more choice can be less - is old news, demonstrated and discussed in consumer research literature of the 1970s and 1980s (Jacoby, Speller, \& Kohn, 1974, and subsequent flurry of responses; Keller \& Staelin, 1987). One of the key contributions of current research, however, is to demonstrate the finding's ubiquity in domains crucial to our well-being-such as retirement investments (Botti \& Iyengar, 2006; Iyengar, Jiang, \& Huberman, 2004; Iyengar \& Kamenica, 2006), credit loans (Betrand et al., 2005), and modern variants of mate choice (Fisman et al., 2006; Lenton, Fasolo, \& Todd, 2009).

\section{EFFECTS OF ASSORTMENT SIZE AND ENTROPY ON QUALITY AND DIFFICULTY OF CHOICE}

Having shown the potentially detrimental effects of offering consumers large assortments, researchers are now starting to explore psychological mechanisms of the too-much-choice effect, as well as moderators of it (see also Fasolo, Carmeci, \& Misuraca, 2009; Haynes, 2009; Jessup et al., 2009; White \& Hoffrage, 2009). The quality of any choice and the difficulty people have in deciding, for instance, have been shown to depend not only on the size of the assortment but also on display. For instance Broniarczyk, Hoyer, and McAlister (1998) found that a smaller sized product offering could actually be perceived by consumers to offer greater assortment than a larger sized product offering when it included consumers' favorites or occupied a larger total shelf space. Hoch, Bradlow, and Wansink (1999) found that, holding product-offering size constant, assortment perceptions could be increased if products were dissimilar and offered unique 
features. Van Herpen and Pieters (2002) found that although product-offering size exerted a significant influence on assortment perceptions, attribute dispersion and disassociation exerted an even greater influence.

Relevant to consumers' choice and choice difficulty, van Herpen and Pieters (2002) emphasized the role of assortment entropy. Entropy is a measure (based on information theory; Shannon \& Weaver, 1949; Garner, 1962) that quantifies the amount of information of a set of objects (measured in bits; Scott's "H," 1969; Zinkhan \& Braunsberger, 2004). To intuit: Entropy is related to complexity, with high-entropy sets of objects being more complex than low-entropy sets. In the consumer context, the entropy of an assortment combines two important structural features of consumer products: the number of attribute levels and the distribution of products on the attribute levels (Hoch, Bradlow, \& Wansink, 2002; van Herpen \& Pieters, 2002; Lurie, 2004). Take an assortment of yogurts for illustration. Yogurts vary on several attributes, such as fat content, amount of sugar, and calorie content. On each attribute, an assortment can have different attribute levels. An assortment of yogurts can, for instance, have different fat contents, and these distinct fat content values represent the number of levels on the attribute "fat content" within the assortment. Depending on how the products are distributed across the attribute levels, distributions may be either even (i.e., each attribute level attracts the same number of products) or uneven (only one or maybe a few attribute levels attract more products than other levels).

Both number of attribute levels and attribute levels' distribution relate to entropy. As Lurie (2004) showed, entropy is high when products are evenly distributed across the attribute levels and when the number of attribute levels is large. Psychologically, entropy appears to tap into people's perception of variety and complexity: Consumers perceive more variety in assortments with higher entropy, and they rate assortments with higher entropy as more complex (Kahn \& Wansink, 2004). From this it should follow that high entropy equals greater choice difficulty and lower choice quality, but how does this relate to assortment size? In order to find how entropy affects the quality of choice in assortments of different sizes, Lurie (2004) manipulated assortment size and components of entropy (number of attribute levels and product distribution) orthogonally. He conducted simulations of hypothetical customers in four product environments: a large assortment with high entropy (i.e., with many attribute levels and/or even product distribution), a large assortment with low entropy (with few attribute levels and/or uneven product distribution), and two small assortments, one with high entropy and one with low entropy. Five classic choice strategies (e.g., elimination by aspect and weighted additive rule) were simulated, and choice quality was measured against the performance of the weighted additive strategy (as in most simulations of multi-attribute choice heuristics, e.g., Payne, Bettman, \& Johnson, 1993). The simulation results were intriguing: Large assortment size was found to decrease choice quality; that is, quality was found to be poorer in large rather than small assortments. Higher entropy was found to increase choice quality; that is, quality was poorer in low-entropy sets with few attribute levels and uneven distribution than it was in high-entropy assortments with more attribute levels and even distribution.

Lurie's (2004) results highlight the importance of considering the effect of entropy on choice quality, together with the usual considerations given to size, but pose a conundrum when considered side by side with other studies of too much choice: Would people make better or worse choices in large supermarket 
assortments, which typically offer large size, great variety, and complexity, and therefore, most likely, higher entropy? Lurie's simulation studies show that choosing from larger assortments would, on the one hand, be more complex and time consuming than choosing from smaller assortments, but, on the other hand, the higher entropy associated with larger assortments could counteract and possibly even offset the negative effect of large size on choice quality.

In Lurie's analysis, size and entropy were manipulated orthogonally, thus implementing psychology's predominant experimental design that Brunswik (1955; Dhami, Hertwig, \& Hoffrage, 2004) termed "systematic design." Using systematic design, in Brunswik's view, exacts the risk of destroying the natural texture of the environment, and therefore jeopardizes the generalizability of the experimenter's conclusions. In the marketplace, the relationship between entropy and size may not at all be orthogonal, as in Lurie's simulated environments. Entropy and size, for instance, may be negatively related in the marketplace; that is, larger assortments exhibit lower entropy, whereas smaller assortments exhibit higher entropy. In this case, following Lurie's simulation results, entropy would work hand in hand with size, with low entropy leading to poorer quality choices and large size rendering choice more difficult compared with small, high-entropy assortments.

The first goal of our investigation is to provide a definitive answer to how entropy and size actually relate in the marketplace. To accomplish this, we need to venture outside the laboratory and investigate the entropy structure of large and small assortments offered by real stores.

\section{EFFECTS OF ASSORTMENT DENSITY ON DIFFICULTY OF CHOICE}

A second, relatively little explored construct that we aim to investigate in relationship to size of real-world assortments is density. By "density," we mean the distance, measured one product attribute at a time, between one product and its closest neighbor. Density is inversely related to "attribute variability," because assortments with dense attributes contain products that have very similar attribute values. Shugan (1989) illustrates this with the example of ice cream: an assortment consisting of the three flavors of chocolate, chocolate chip, and fudge has less attribute variability than an assortment consisting of the three flavors of chocolate, vanilla, and strawberry. Flavor is thus more "dense" and less variable (concentrated on the chocolate/creamy end of the spectrum) in the first than the second line.

Shugan (1980) was among the first to suggest that choice difficulty increases as "density" (or, as he wrote, "differences in utility between products") decreases; that is, as the products' attribute values become more similar to one another. Subsequent empirical studies support this claim. For instance, Dhar (1997) showed that the tendency for consumers to defer choice (a measure of choice difficulty, as demonstrated by Dhar, 1996) increases when the difference in attractiveness among products is small, rather than large. Conceptually, this happens because consumers find it easier to make up their minds and choose a product when the products on offer have very disparate values (e.g., two yogurts contain $10 \mathrm{~g}$ vs. $0.1 \mathrm{~g}$ of fat) rather than very similar (e.g., $2.5 \mathrm{~g}$ vs. $3 \mathrm{~g}$ ). Dense assortments thus 
carry the risk of making it difficult for consumers to tell the difference between products on any specific attribute.

The relationship between dense assortments and difficult choice also emerges in other studies that have examined the amount of information acquired before making a choice. Biggs et al. (1985) showed that bank loan officers acquired more information and in a more systematic fashion for loan applicants who were very similar to one another on attributes of interest (e.g., similar values on financial statement strength), relative to dissimilar applicants (differences were large). Similarly, Böckenholt et al. (1991) observed that decision makers choosing between vacation locations and restaurants searched for more information when the options differed little rather than a lot on attributes of interest (e.g., in temperature, number of rainy days).

Dense assortments thus appear to make choice difficult. The second goal of this research is to examine whether density is a hidden player that accounts for why large supermarket assortments render choice difficult. If larger assortments are achieved by adding products within an existing attribute range, rather than by expanding the attribute range, then adding new products will increase the density on this attribute. For illustration, consider a retailer pondering which yogurts to offer to consumers. Her problem can be reframed as that of populating the yet empty multi-attribute space with the available yogurts. One of the attributes for yogurts is fat content. Figure 1 illustrates this attribute's hypothetical maximum scope of levels, ranging from fat-free to full-fat, for a small and a large assortment, respectively. The small assortment (left) consists of three yogurts, A (fat-free), B (low-fat), and C (high-fat); the large one consists of nine yogurts (right). Given a fixed attribute range (from fat-free to the maximum fat content of Greek yogurts), the more yogurts with different fat-content levels that the retailer places on the shelf, the smaller the distance (henceforth, interproduct distance) between any two yogurts (ordered by increasing fat content). This reveals the downside of trying to offer something for everyone. Given a finite range of attribute values, the goal to accommodate a wide customer base, from the calorie-counting dieter to the taste-is-everything gourmet, risks giving rise to an assortment with closely packed attribute spaces and small interproduct distances (i.e., with high density).

Our hypothesis is that in their quest to offer "something for everyone" within a finite range of attribute values, large assortments are more likely than small assortments to overcrowd the attribute space with products that are very close (but not identical) to other products. Density thus would exacerbate the tyranny

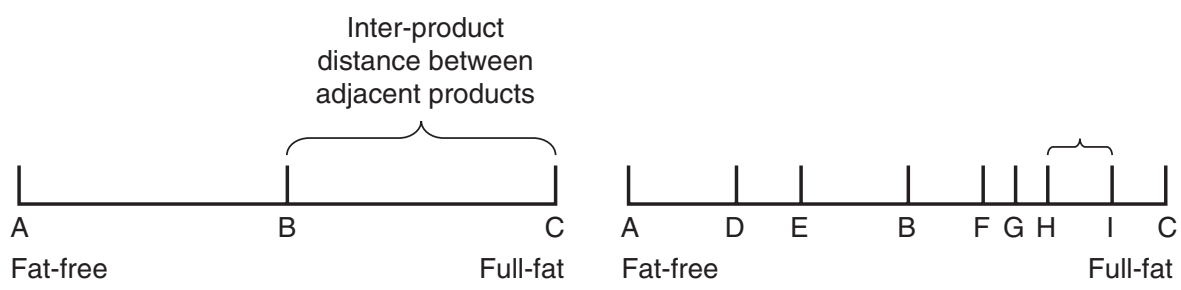

Figure 1. Illustration of the hypothesized negative empirical relationship between density (measured in terms of inter-product distance on the fat content attribute; for a similar representation; see Johnson, 1971) and size for a yogurt assortment (left: small, and right: large). 
of choosing from large assortments, with large, high-density assortments leading to more difficult choices than small, low-density assortments. However, let us emphasize that larger assortments need not be denser, for two reasons. First, rather than targeting the whole range of attribute values, small supermarket assortments may cater to a specialized taste-for instance, just offering a few very exquisite, expensive wines. However, if they do so, then small assortments may in reality be even more densely packed (in a smaller range) than large assortments; thus density in small assortments may thwart the beneficial effect of small assortment size on choice difficulty. Second, as Lehmann (1998) pointed out, a large assortment can also be achieved by expanding the attribute range. For instance, plasma televisions today come in a range of sizes, from 37 inches upwards. The biggest plasma TV on the market today has a 103-inch screen (http://www.plasmatvbuyingguide.com/plasmatv-screensize.html; retrieved September 18, 2008). Adding a 150-inch screen to an offer of, say, 37, 45, and 65 inches would not increase the density of the assortment; however, adding a 47-inch screen would.

To summarize, this article is concerned with two environmental properties of assortments, namely, entropy and density. Both have been investigated as determinants of choice quality and choice difficulty, but primarily in the laboratory and not in explicit relationship with assortment size. The paper consists of two parts. First, we analyze the relationship between entropy and density structure in several real-world assortments offered by a small and a large store, respectively. Second, we simulate choice in the same supermarket assortments, thus shedding some light on the psychological consequences of choosing from them.

\section{ASSORTMENT SIZE, DENSITY, AND ENTROPY: HOW DO THEY RELATE IN THE MARKETPLACE?}

In order to investigate the relationship between size, entropy, and density in the market, we recorded the attribute structure of 12 product categories offered to customers by two popular stores in Germany. The assortments chosen satisfied the following criteria: They (1) were offered in both stores, (2) consisted of common consumer products of everyday use in German households, and especially (3) contained easily and clearly recordable attributes and attribute levels. Our focus on an extensive set of products, attributes, and attribute values, and on analyzing their statistical structure as a function of assortment size distinguishes our analysis from previous scanner panel analyses (e.g., Zhang \& Krishna, 2007, considered only three product categories; Borle et al., 2005, did not record attributes; Boatright \& Nunes, 2001, 2004, only considered the three attributes of brand, size, and flavor).

The product categories were yogurt, curd cheese, quark, butter, margarine, toast, mustard, jam, pasta, toilet paper, soluble coffee, and milk. The two stores analyzed were both part of successful supermarket chains. One store (small store) is renowned for its explicit philosophy of offering little choice; the other (large store) offers lots of choice. The data were collected over a period of three weeks. For each product, all the attributes (e.g., fat content, flavor, type of package, price) and respective attribute levels (e.g., fat grams per $100 \mathrm{~g}$ ) that a customer could see were recorded on a pocket PC. The type and the number of 
attributes varied as a function of product category. ${ }^{1}$ For purposes of comparability, the same attributes were recorded for each product category in the large and small store. For each product category, we calculated its size, entropy, and density, as follows:

Size. Size of assortment equals the number of products a customer could choose from within a particular product category. Only visible products on the shelf were counted. Each product was counted once regardless of how many stockkeeping units (SKUs) were available. An assortment is therefore composed of different products, not stocks.

Entropy. We measured entropy in two ways. First, intra-attribute entropy scores were computed for each attribute in our data set. Formally, the intraattribute entropy $I E_{k}$ of an attribute $k$ is:

$$
I E_{k}=-\sum_{j=1}^{z_{k}} p\left(a_{j, k}\right) \ln p\left(a_{j, k}\right),
$$

with $p\left(a_{j, k}\right)$ denoting the proportion of products with attribute level $a_{j, k}$ and $z_{k}$ representing the total number of attribute levels for attribute $k$ (van Herpen $\&$ Pieters, 2002). Intra-attribute entropy measures the complexity of the assortment structure separately for each attribute of a product category. In order to capture the complexity of the total product category across different attributes, we also determined the product-category entropy score $(P C E)$, as the sum of all intra-attribute entropies within the product category:

$$
P C E=\sum_{k} I E_{k},
$$

with $I E_{k}$ being the intra-attribute entropy of attribute $k$. The two entropy measures were calculated both for quantitative and qualitative attributes.

Density. Density of an assortment was measured in terms of mean interproduct distance; that is, the average distance between two adjacent attribute levels within a product attribute (Figure 1). Formally, the interproduct distance of attribute $k, I D_{k}$, is equivalent to the attribute value range, $a_{\max , k}-a_{\min , k}$ for attribute $k$, divided by the number of attribute levels, $z_{k}$, minus 1 :

$$
I D_{k}=\frac{a_{\max , k}-a_{\min , k}}{z_{k}-1} .
$$

Because the mean distance is a range-dependent measure, we also computed the median and mode interproduct distance, so that the density comparison was not confounded by a possible difference in attribute range between the small and large assortments. Density was only measured for quantitative attributes.

\section{Analyzing the Marketplace: Findings}

How much bigger is the large assortment, relative to the small assortment? Table 1 describes the assortment structure of the 12 product categories in our study. Across all product categories the large store offered, on average, about eight times more products than the small store $\left(M n_{\text {large }}=54 ; \mathrm{SD}=63.3\right.$ and $M n_{\text {small }}=7$;

1 The complete data set including all products, their attributes, and respective attribute levels are available on request from the first author. 
Table 1. Descriptives of the 12 Supermarket Assortments (Number of Products, Attributes, Attribute Levels, and Qualitative Attributes) by Large and Small Store.

\begin{tabular}{|c|c|c|c|c|c|c|}
\hline \multirow{2}{*}{$\begin{array}{l}\text { Product } \\
\text { Category }\end{array}$} & \multicolumn{2}{|c|}{ \# Products $n$} & \multirow[b]{2}{*}{ \# Attributes $m$} & \multirow{2}{*}{$\begin{array}{c}\text { \# Qualitative } \\
\text { Attributes }\end{array}$} & \multicolumn{2}{|c|}{$\begin{array}{l}\text { \# Attribute } \\
\text { levels } z\end{array}$} \\
\hline & Large & Small & & & Large & Small \\
\hline Milk & 22 & 3 & 12 & 5 & 73 & 19 \\
\hline Yogurt & 210 & 26 & 16 & 9 & 416 & 88 \\
\hline Quark & 97 & 9 & 11 & 5 & 239 & 36 \\
\hline Speisequark & 12 & 2 & 8 & 6 & 46 & 11 \\
\hline Butter & 20 & 1 & 11 & 8 & 48 & 11 \\
\hline Margarine & 21 & 4 & 10 & 4 & 71 & 26 \\
\hline Toast & 9 & 6 & 11 & 4 & 54 & 30 \\
\hline Mustard & 18 & 2 & 6 & 4 & 30 & 7 \\
\hline Jam & 138 & 13 & 9 & 9 & 173 & 31 \\
\hline Pasta & 58 & 8 & 9 & 6 & 97 & 30 \\
\hline Soluble coffee & 11 & 3 & 4 & 2 & 21 & 8 \\
\hline Toilet paper & 27 & 2 & 7 & 5 & 54 & 11 \\
\hline$A V E R A G E$ & 54 & 7 & 10 & 6 & 110 & 26 \\
\hline
\end{tabular}

$\mathrm{SD}=9.42 ; t(22)=2.5 ; p=.003)$. The largest product category was yogurt, with 210 and 35 products in the large and small store, respectively. About $60 \%$ of the attributes were qualitative (e.g., color) and the rest were quantitative (e.g., price). We note that this structure, especially that of the large store, appears more complex and disparate than that commonly assumed in previous experimental or simulation studies manipulating assortment size.

How are size of assortment and entropy related? Before we turn to the entropy measure, let us first consider two structural components of entropy. The first component-average number of attribute levels (see $z$ in Table 1) was found to correlate strongly with the number of products in the assortment $[r(24)=0.962]$ : Large assortments have more attribute levels than small assortments. Regressing number of attribute levels on number of products, we found that for each additional product in the assortment, the number of attribute levels increases by 1.76 (unstandardized beta $=1.76$ ), suggesting that each product adds levels on more than just one attribute, possibly reflecting a deliberate marketing strategy. No notable relationship with size was found, however, for the second structural component of entropy - the distribution of products along the attribute space. Figure 2 illustrates the general result for yogurt fat content: The distribution of yogurts proved to be largely uneven on fat content, both for the small and large assortments. The figure also illustrates the positive relationship between the range of attribute levels and the size of the set: The larger yogurt assortment presents the consumer with a substantially greater range $(0.1-15.0 \mathrm{~g})$ of fat content levels than the smaller assortment: $(0.1-10.0 \mathrm{~g})$. This range difference between small and large supermarkets makes it all the more important to include range-independent measures of density, like the median and mode interproduct difference.

Turning to our key analysis of the relationship between entropy and size, intra-attribute entropy was more pronounced in the large store than in the 


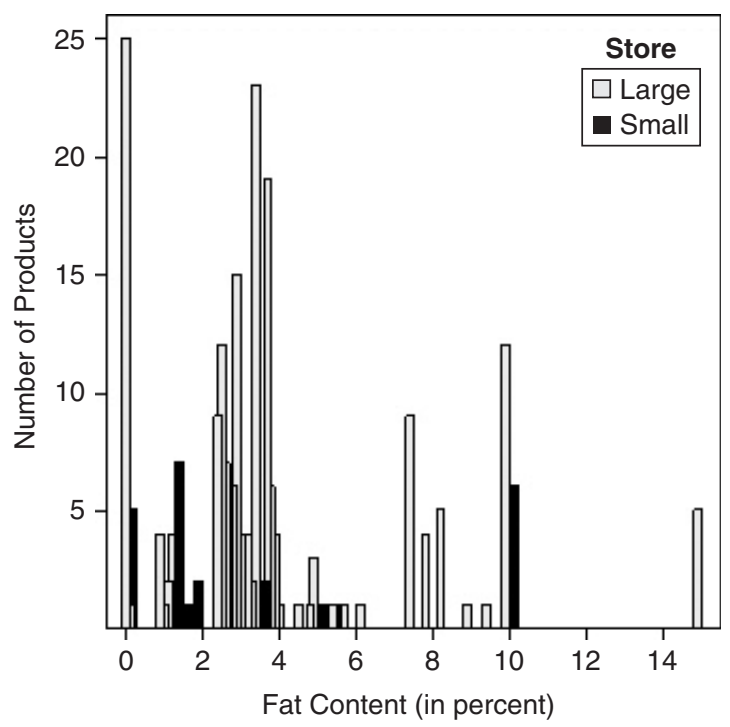

Figure 2. Distribution of yogurts on the "fat content" attribute, by small and large store.

Range and Average IE by product category

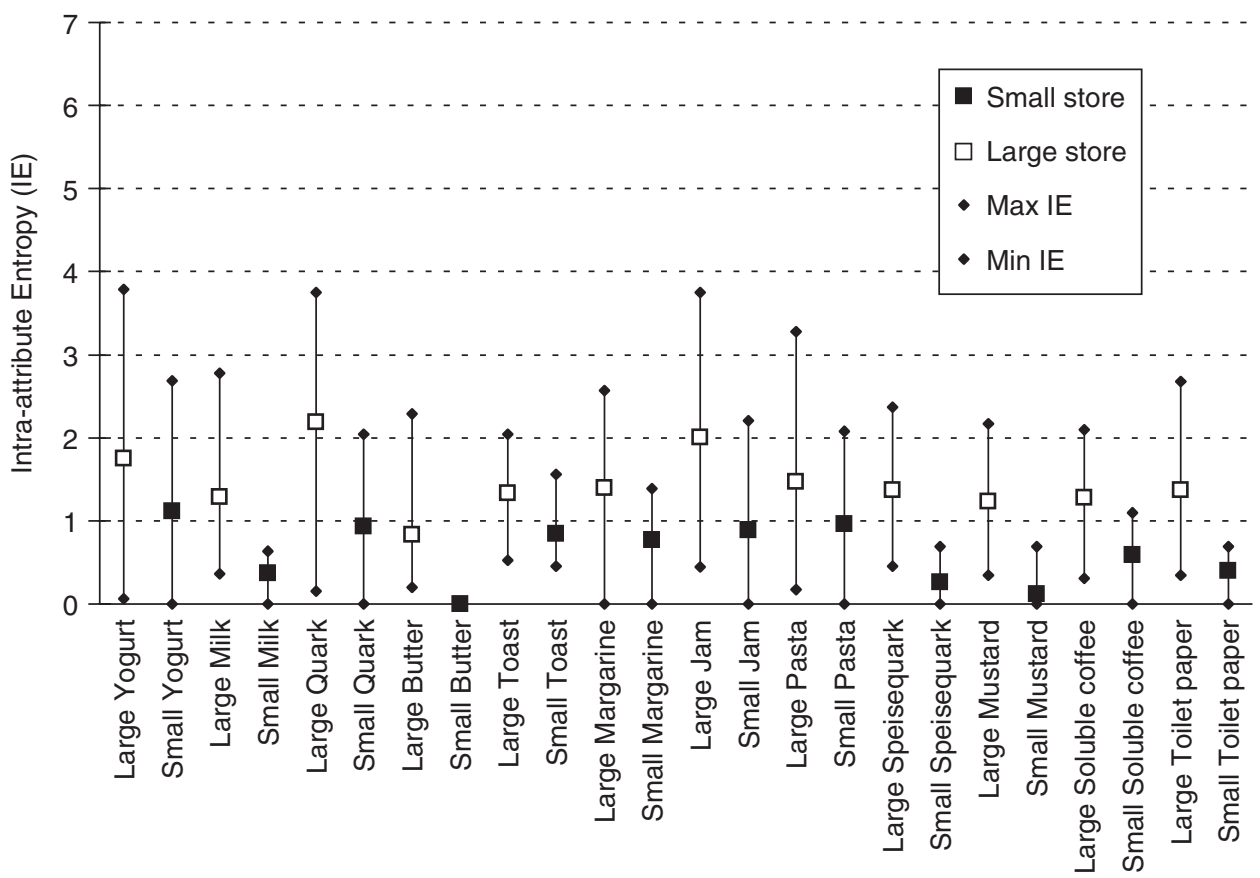

Figure 3. Distribution (range and average) of intra-attribute entropy (IE) by large and small store, for the 12 supermarket categories.

small store. Specifically, intra-attribute entropy was on average larger in the large store $\left(M n I E_{\text {large }}=1.46, \mathrm{SD}=0.36\right)$ than in the small store $\left(M n I E_{\text {small }}=0.62\right.$, $\mathrm{SD}=0.37 ; t(22)=5.6, p<.0001)$. This was true across all product categories. Figure 3 shows the range and average intra-attribute entropy separately for 
the large and small store and across all 12 product categories. The same result emerged for the product-category entropy, which is the sum of all intra-attribute entropies within the product category. On average, the product-category entropy in the large store $\left(M n P C E_{\text {large }}=14.08, \mathrm{SD}=6.7\right)$ was higher compared with the small store $\left(M n P C E_{\text {small }}=6.17, \mathrm{SD}=5.15 ; t(22)=3.24, p<.005\right)$.

Besides showing how size and entropy are related in the marketplace, analysis of intra-attribute entropy and product-category entropy can also tell us which attributes of a given product contribute most to the overall entropy, and therefore to the perception of complexity in the mind of the consumer. By dividing the entropy of each attribute in a given product category by the entropy of the category, we determined the extent to which each attribute contributes to the product-category entropy. Table 2 reports the three attributes that contribute most. Brand and price stand out as making up the largest share of the product-category entropy across most product categories. The only exceptions are yogurt and quark, for which the attributes that contribute most are flavor and calories $(\mathrm{kJ})$. Flavor is also a large contributor for jam, along with brand. Shape, on the other hand, is the largest contributor for pasta, again along with brand. These results give novel insights into possible ways to change the entropy of a product category, as we will discuss below. Further, these insights were rendered possible by a focus on the assortments' "attributes structure" rather than the composition in terms of products as is the typical focus of earlier scanner panel analyses (e.g., Boatwright \& Nunes, 2001, 2004; Borle et al., 2005; Zhang \& Krishna, 2007).

How are size and density related? The average interproduct distance (ID; that is, the average distance between two adjacent attribute levels) was computed for each of the continuous attributes (e.g., amount of carbohydrate in toast) with more than one attribute level, for each product and product category. Because each attribute is measured in different currencies (grams, \%, $\mathrm{kJ}$, etc.), we report the comparison of interest as the proportion of cases in which the mean ID was larger in the small than in the large store out of all the valid cases (i.e., all the cases where the mean ID in the small store was different from the mean ID in the large store). We found that in $80 \%$ (33 out of 41) of the comparisons, the small store assortments had, as hypothesized, a larger mean ID compared with the large store. This is a large effect, especially considering that the mean ID is range-dependent and that, as seen above, the range was typically larger in the large than in the small store. A similar result emerges from the median interproduct distance: Here we found that in $75 \%$ (30 out of 40) of the comparisons the median ID was, as hypothesized, larger in the small than in the large store.

Converging results emerge from analysis of the mode IDs, although the number of comparisons was much smaller due to the fact that mode IDs are very rare in the small assortments, which typically offer few products, all with differing attribute values. Consequently, out of all the attributes and across all product categories, mode IDs could be computed for both small and large stores on only five attributes. Of these five, the mode ID was identical in the large and small store in two cases. In the three remaining cases, the mode ID was, as hypothesized, larger in the small than in the large store in all three cases (fat content for yogurt: 0.1 in large and 0.3 in small store; price for yogurt: 0.05 in large and 0.1 in small; and price for quark: 0.05 in large and 0.4 in small). 


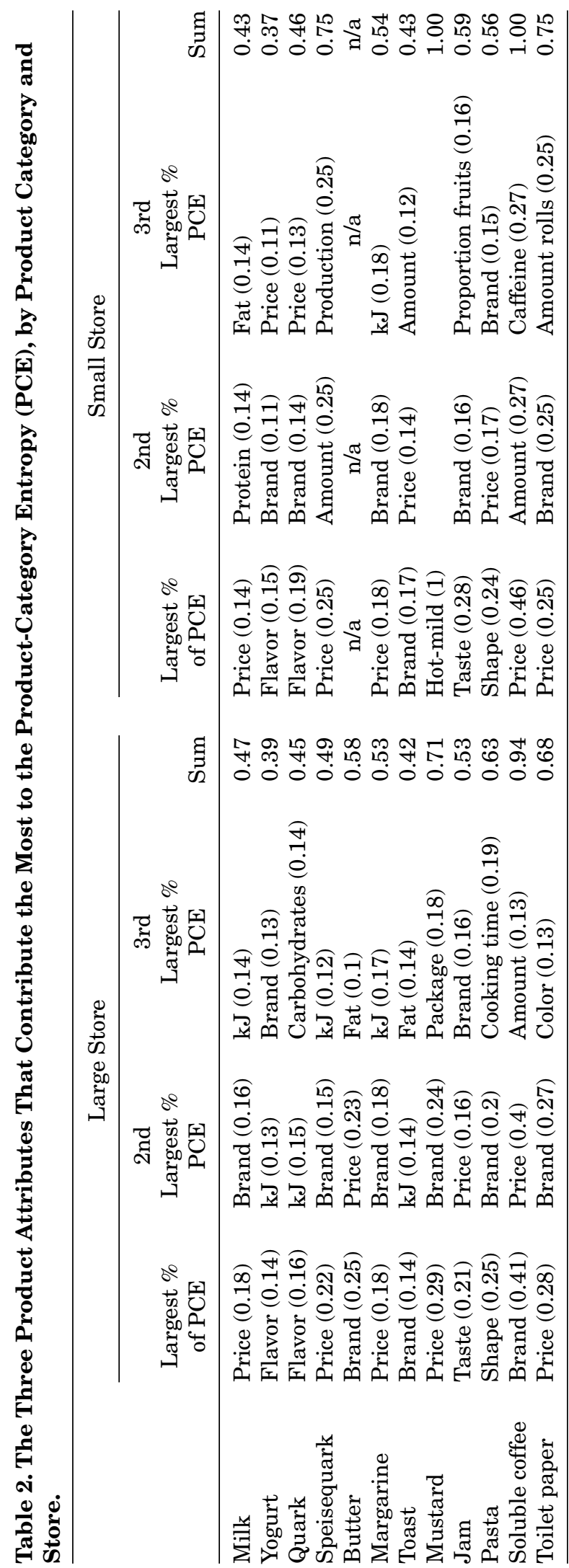




\section{DISCUSSION: THE STRUCTURE OF THE MARKETPLACE}

Our supermarket assortments analysis revealed a close relationship between size, density, and entropy. First, we found that larger assortments also tend to be the denser ones; that is, they have smaller interproduct distances, per attribute. In addition, we observed that larger assortments also tend to be those with higher entropy. Entropy analyses showed that the small low-density assortments in the marketplace have lower entropy than large high-density assortments. This indicates that in the marketplace small assortments combine two attractive properties: They offer less density and less information. Each of these properties alone has been demonstrated experimentally to render choice easier and less complex (Dhar, 1997; Kahn \& Wansink, 2004; Lurie, 2004). At the same time, however, larger assortments might hide an ace up the sleeve because of their higher entropy, which has been shown in simulations to lead to higher choice quality (Lurie's 2004, simulation study). The implications of large and high-entropy assortments on difficulty and choice quality are thus addressed in the simulation section below in the context of supermarket assortments, rather than hypothetical assortments that manipulate these dimensions orthogonally.

What causes the lower entropy of our small, low-density assortments? Is it the consequence of a deliberate product line strategy adopted by the small store or is it just a technical property of the statistic when computed over a small size? To explore this issue further, we computed the entropy of four artificial assortments. These four assortments were a subset of the small and large assortments examined by Lurie (2004). As in Lurie, the small assortment was composed of 8 products and the large assortment of 16 products, varying on four attributes. These assortments differed from one another on the number of attribute levels per attribute ( 2 vs. 4 ) and distribution of options along attribute levels (even vs. uneven). In the case of two attribute levels with uneven distribution of options, three-fourths of the products took one attribute value, whereas onefourth of the products took the other value. In the case of four attribute levels with uneven distribution of options, five-eighths of the products took one attribute value, and each of the remaining three eighths of the products took one of the remaining three attribute values.

If indeed the lower entropy of our small, low-density assortments is due to an explicit product-line strategy, the entropy for the marketplace and artificial assortments should be different; if the lower entropy of small assortments is a statistical artefact, the two sets of values for real and artificial should be similar. As Figure 4 indicates, the entropy of the small marketplace assortments lies in the "middle," exactly between the entropy of the two artificial small assortments (small, low entropy and small, high entropy). The figure further shows that the entropy of marketplace assortments in the large store is higher than that in the artificial assortments simulated. One last result to note is that this analysis effectively replicates Lurie (2004), by showing that small sets can have higher entropy than large sets. For instance, our artificial set of 16 options has lower entropy (0.56) than the artificial set of 8 options (1.39), when the large set has uneven distribution of options along two attribute levels and the small set has even distribution of options along four attribute levels. As seen earlier and represented in the figure, the finding of large and low entropy sets is hardly representative of the marketplace, in which smaller sets are typically lower in entropy. 


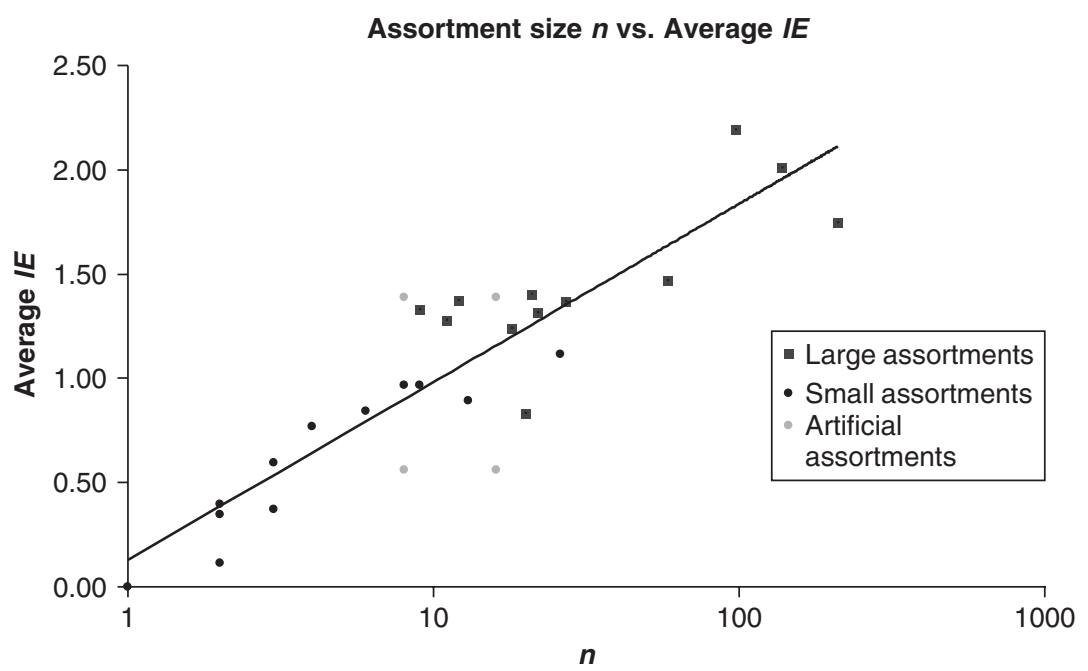

Figure 4. Size $(n)$ and entropy (average $I E$ ) orthogonally related in four artifical sets simulated by Lurie (2004) compared with size and entropy as naturally related in our small and large supermarket assortments.

\section{MAKING CHOICES IN THE MARKETPLACE}

In the two supermarkets investigated here, large assortments tended to be complex and dense, relative to small assortments. How do these information structures impact on decision makers? Concerning choice difficulty, the expectations are relatively straightforward. Drawing on previous research (e.g., Lurie, 2004; Dhar, 1997), we predicted that it is more difficult to choose from large, highdensity, high-entropy assortments than from small, low-density, low-entropy assortments. Adopting the standard measure in previous research, we defined the amount of information seen before making a choice as a proxy for decision effort and, by extension, choice difficulty.

Concerning the quality of choice-as measured against the benchmark weighted additive strategy (as in Lurie, 2004, and many other analyses) - the expectations are less straightforward. On the one hand, we expected simulated choice quality to be higher in small assortments than it is in large assortments, as Lurie's results on the effects of assortment size on quality suggest. On the other hand, in our real-world assortments the reverse could also be true: Because the assortments in our small supermarket tend to be lower in entropy, and given that in simulations lower entropy appears to be associated with lower choice quality (Lurie, 2004, Study 3), it is possible that choice quality is lower in small supermarket assortments than it is in large supermarket assortments. Previous research, where entropy was measured "distally" by its two components (number of attribute levels, many vs. few, and distribution of options on the attribute levels, even vs. uneven), is thus inconclusive about the net effect of high entropy and large size on choice quality. In addition, previous studies (Lurie, 2004; Kahn \& Wansink, 2004) varied size and components of entropy orthogonally. In contrast, we investigated choice quality and choice difficulty in the context of our supermarket assortments, in which large size and high entropy co-occur and have a much larger range than in previous laboratory settings (see Figure 4). 


\section{Method}

As can be seen in Table 1, the amount of information (e.g., number of products and attributes) varied greatly across the 12 product categories, with yogurt constantly at the maximum of the range. Out of consideration for parsimony and representativeness at the same time, we ran our simulation analyses on the three most "representative" categories of the whole range (methodological reasons for this choice are explained in McClelland, 1997). The assortment representative of the low end of the information load spectrum was margarine; the assortment representative of the middle of the range was pasta, and finally the assortment representative of the high end of the range was yogurt. In each of these three assortments, we simulated a total of ten choice strategies. For each of these strategies, we measured the simulated consumer's choice quality and difficulty, when using one of these strategies in either the small or the large assortment.

Choice strategies. Different consumers use different, and different combinations of, choice strategies. To take this simple truth into account and to examine the behavior of different consumers in the environments of the small and large store assortments, respectively, we examined ten often-discussed choice strategies (Lurie, 2004; Payne, Bettman, \& Johnson, 1988). In the context of our simulations, each strategy can be thought of as a method for searching through the assortment and making a choice. This search method may reflect information about such aspects as the relative standing of a product on a feature of interest (e.g., amount of calories) and comparison of this value against cut-off values specifying a minimal acceptable level for that attribute.

The choice strategies we simulated can be grouped according to a major distinction frequently discussed in the literature: the extent to which they make trade-offs among attributes. Strategies that allow for such trade-offs are called compensatory strategies, whereas strategies that forsake trade-offs are referred to as non-compensatory. Four of the ten choice strategies simulated are noncompensatory (Hastie \& Dawes, 2001): LEX (lexicographic strategy), SEMILEX (lexicographic semi-order strategy), $E B A$ (elimination by aspect strategy), and $S A T$ (satisficing strategy). Three of the ten strategies are compensatory: WADD (weighted additive strategy), $E Q W$ (equal weight strategy), and $M C A$ (most confirming attribute strategy). Individuals sometimes use combinations of strategies. One mixed strategy that is frequently observed is $E B A+W A D D$ (elimination by aspect plus weighted additive rule); another combination strategy is $E B A+M C D$ (elimination by aspect plus most confirming dimensions). Last, we also simulated a strategy that randomly makes choices, $R A N$. The task of each choice strategy was to search through the space of products and related attributes within a product category and select the best product. We shortly define how we determined the best choice.

Shopping environment. For the reasons indicated above, the information structure of the simulation environments reflected the structure that evolved in the two stores for the three product categories of yogurt, pasta, and margarine. Table 1 describes the three product categories in terms of their number of products, attributes, and attribute levels.

Preference for product attributes. As is customary in decision analytic techniques (e.g., von Winterfeldt \& Edwards, 1986), attribute values were rescaled 
on a scale from 0 to 1.0 (by dividing by the maximum, so that the maximum was 1.0 and minimum was 0.0). As in Lurie (2004), cut-off levels of 0.3 and 0.5 of the maximum attribute range of 1.0 were set for the satisficing $(S A T)$ and elimination by aspects $(E B A)$ rules, respectively. The error margin of the justnoticeable difference for $S E M I-L E X$ was set to 0.05 of the maximum attribute level in the environment tested. When an attribute was not continuous (e.g., color, flavor, and shape) we replaced its level (e.g., "red") with a numerical value randomly drawn from a uniform distribution between 0 and 1 (as in Lurie, 2004). These attributes, too, were then rescaled so that for each attribute the maximum value was 1 and the minimum value was 0 .

To test for the generalizability of our results across customers with different aspirations with regard to supermarket assortments, attribute rescaling was performed in two ways. Each reflects a different view of what a customer considers the "best" or ideal product. The first preference structure simulated is consistent with the notion of a customer, Joe Average, who would be happy with the best product in the store he is visiting, be it large or small. Furthermore, this customer's preference is assumed to increase monotonously over the attribute range offered by the store's products (i.e., the more of an attribute, the better). Accordingly, rescaling of the attribute values is performed with reference to the maximum of the attribute values in a given store (henceforth, local rescaling). Technically speaking, this means that a given attribute value will have a transformed value of 1 in the small store when it is equal to the maximum value in the small store $\left(a_{\text {small, max }}\right)$ and a value of 1 in the large store when it is equal to $a_{\text {large }, \max }$, where typically $a_{\text {small, } \max } 1 \neq a_{\text {large } \max }$ (and frequently $a_{\text {small, } \max }<$ $\left.a_{\text {large, max }}\right)$. Similarly, a given attribute $a$ will have a transformed value of 0 in the small store when it is equal to the minimum value in the small store $\left(a_{\text {small, } \min }\right)$ and a value of 0 in the large store when it is equal to $a_{\text {large, min }}$.

This rescaling is consistent with the widely held notion that preferences and aspirations are "constructed" (for a review, see Lichtenstein \& Slovic, 2006). Consequently, what is best or worst depends on the products available in that assortment. Joe Average would thus be most satisfied with the product that, in the assortment of that particular store, has the maximum value across all the attributes. Although a product that has the most desirable value on all attributes is certainly attractive, such an ideal product may be a luxury that does not exist in reality. The reason is that attributes are often negatively related and although a product might have a high value on one attribute it might also have a low value on another set of attributes, as is often the case for products in the same price range. For this reason, in our simulations the product with the highest overall value does not necessarily have the highest value of 1 on all attributes.

The second preference structure simulated is consistent with the notion of a customer, Jane Fuzzle, who is pickier than Joe Average, and would find maximum satisfaction only if she selected the best product out of both stores. Accordingly, rescaling is performed with reference to the maximum value across both stores, or $\operatorname{Max}\left(a_{\text {small, } \max }, a_{\text {large, } \max }\right)$. This rescaling (henceforth referred to as global scaling) implies that a given attribute will have a transformed value of 1 only if it is equal to $\operatorname{Max}\left(a_{\text {small, max }}, a_{\text {large, max }}\right)$. Similarly, a given attribute will have a transformed value of 0 in the small store when it is equal to the $\operatorname{Min}\left(a_{\text {small, } \min }\right.$, $\left.a_{\text {large } \min }\right)$. Again, it is possible that this "super product" exists only in the consumer's mind, but not in reality. 
By crossing the two customer profiles with the ten choice strategies, we are able to simulate 20 different types of consumers. Of course, many other profiles are possible-in terms of either other choice strategies or other preference functions (e.g., a single peaked preference function; Coombs \& Avrunin, 1977). These 20 types are, however, deemed to be sufficient to test for the difference between choice in a small and large store. Simulations with the global (Jane Fuzzle) and local (Joe Average) customer profiles were performed using the same transformation of categorical attributes. In addition, our simulated Joe Average and Jane Fuzzle saw the products and product information in exactly the same order, thus allowing easier comparisons across both customer types.

Procedure. A simulation was run 1000 times for the three product categories in both small and large stores. At the beginning of each run, the attribute weights were randomly drawn from a uniform distribution between 0 and 1 , and normalized to sum to 1 (as in Lurie, 2004; Johnson \& Payne, 1985; Payne, Bettman, \& Johnson, 1988). For each run, the processing order (that is, the sequence in which products are presented to the simulated decision maker) was randomized.

Measures of choice outcome and process. ${ }^{2}$ The simulations provide two measures, one related to the outcomes (choice quality) and one to the process (choice effort and, by extension, choice difficulty). As a measure of effort, we determined the pieces of information that a strategy needs to look up before making a choice. A piece of information equals the value of the product $i$ on attribute $k$. Conceptually, this measure captures the number of products and attribute values that have to be compared before a choice is made and it well reflects the image of a shopper bouncing from one product to the next before making the choice (Shugan, 1980). It is analogous to the conventional measure of frugality in the heuristics literature (Brandstätter, Gigerenzer, \& Hertwig, 2006).

The effort unit $e_{i, k}=\{0,1\}$, becomes 1 if the value of the product $i$ on attribute $k$ is examined, and 0 if it is not. The total effort for a strategy, $e$ (Strategy), is then the sum of all effort units $e_{i, k}$ (Strategy) over the entire assortment,

$$
e(\text { Strategy })=\sum_{i=1}^{n} \sum_{k=1}^{m} e_{i, k}(\text { Strategy }) \text {. }
$$

The minimum effort corresponds to that of the random choice strategy, $R A N$, which requires an effort of 1 , whereas the maximum effort corresponds to the $W A D D$ strategy and is equal to the number of attributes $m$ multiplied by the number of products $n$ in the assortment, $e(W A D D)=n \cdot m$.

To calculate each strategy's choice quality, $c$ (Strategy), we computed the difference between the weighted additive value of the product chosen by means of a given strategy $\left(E V_{\text {Strategy }}\right)$ and the value of the product with the lowest overall weighted value in the assortment $\left(E V_{\text {Worst }}\right)$ as a proportion of the difference

2 Because our simulation measures were slightly different from Lurie's (2004), we first validated them by running simulations in test assortments that had exactly the same structure as in Lurie. Comparison with Lurie (2004) shows that, in the same artificial assortments, where size and entropy were varied independently, our measures and those of Lurie yield essentially the same results. In particular, just as in Lurie's original study, we found that higher choice quality emerges when there are (1) fewer options or (2) more entropy (more attribute levels and more even distribution). 
between the value of the product with the highest $\left(E V_{\text {Best }}\right)$ and lowest overall weighted value in the assortment (as in Payne, Bettman, \& Johnson, 1988):

$$
C(\text { Strategy })=\frac{E V_{\text {Strategy }}-E V_{\text {Worst }}}{E V_{\text {Best }}-E V_{\text {Worst }}} \text {. }
$$

This measure of choice quality equals the highest value of 1 if the product chosen by a given strategy is the product with the highest weighted additive value. Choice quality will be referred to as global accuracy if $E V_{\text {Best }}$ and $E V_{\text {Worst }}$ are computed with reference to the best and worst product across both stores. Conversely, choice quality will be referred to as local accuracy if $E V_{\text {Best }}$ and $E V_{\text {Worst }}$ are computed with reference to the best product in the particular store environment analyzed.

\section{Results}

We now report choice effort and choice quality as a function of the ten choice strategies, two stores, and two customer profiles, for the three product categories. We begin with the results for choice effort. Drawing on previous research, we expected that making choices in large, high-density, high-entropy assortments requires more effort than making choices in small, low-density, lowentropy assortments. This is exactly what we found. It typically takes more effort to choose the best product from the large supermarket assortments than from the small. The quickest strategy (after $R A N$ ) in both stores was the elimination by aspect strategy.

Unlike for effort, predictions for choice quality were less obvious. We turn to the global accuracy results first. Assuming picky Jane Fuzzle's preference structure, choice accuracy, averaged across all strategies, is higher in the large rather than in the small store (yogurt category: $66 \%$ vs. $49 \%$ ). However, when we turn to local accuracy, reflecting Joe Average's preference structure, the difference in accuracy between the large and small stores reverses (yogurt environment: 67\% vs. 70\%). These results suggest that pickier customers like Jane Fuzzle are those that reap the largest benefits (in terms of choice quality) of a larger, denser, higherentropy assortment over a smaller assortment with less density and entropy. For a customer like Joe Average, who is happy with the best product in the particular store he happens to visit, choosing from a larger store offers no benefits.

Figure 5 highlights the potential trade-offs between accuracy and effort for the various choice strategies (as in Payne, Bettman, \& Johnson, 1988) across the three product categories. A line that indicates an efficient set of strategies, considering both a desire for greater accuracy and a desire for less effort, is drawn for the large and the small assortment, and for both preference structures (i.e., global vs. local). The simulation does not identify which particular strategy a decision maker will select in a given decision environment. That would depend on the degree to which a decision maker was willing to trade decreases in accuracy for savings in effort, and on his or her preference structure. Nevertheless, some key results emerge: First, across the three product categories, strategies require less effort in the small than in the large supermarket assortment, across both customer profiles: In Figures 5a-c, effort is typically lower for all strategies in the small store than in the large store. This difference does not depend on the type of customer preference assumed (see similar large-small differences 


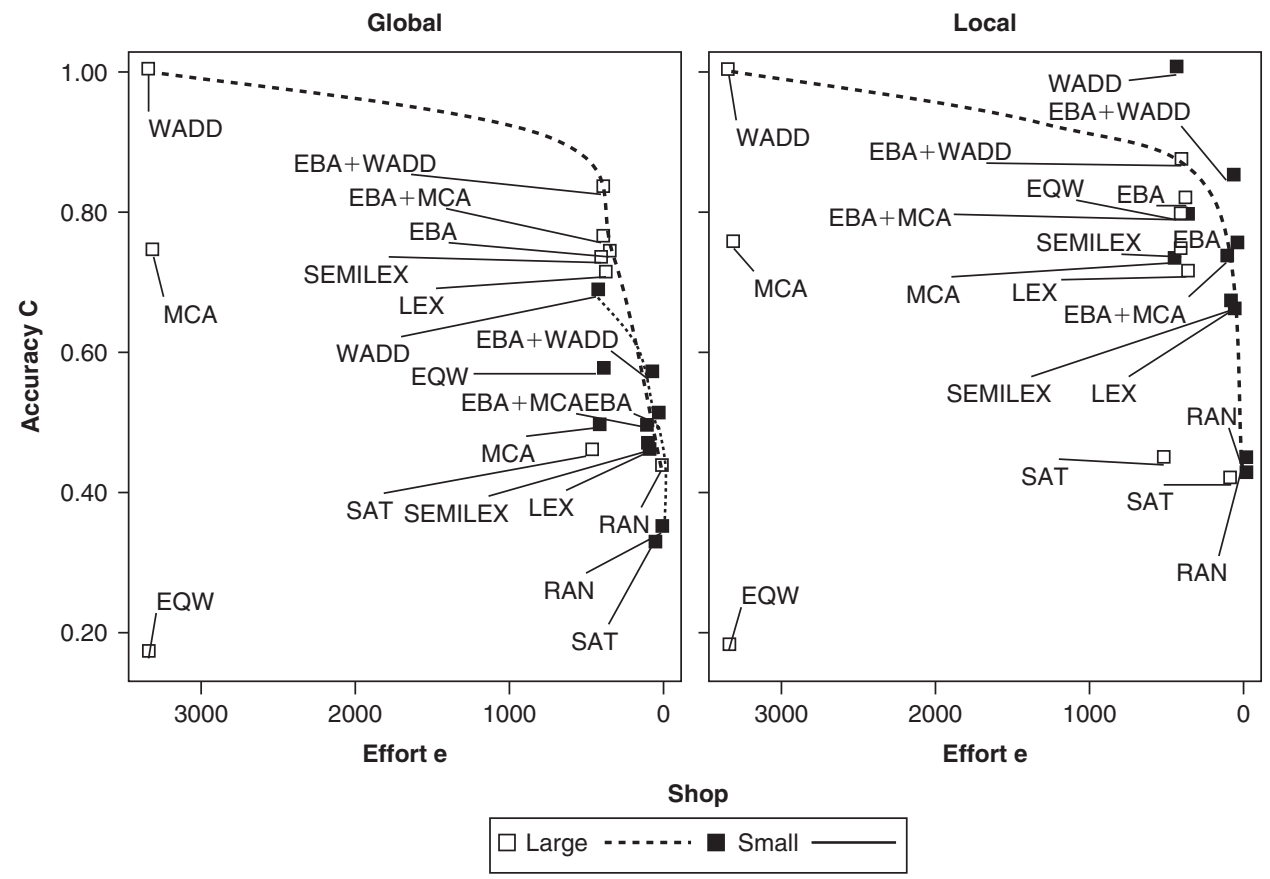

Figure 5a. Accuracy-effort frontier of the ten simulated strategies, for the yogurt product category and two customer profiles (global and local).
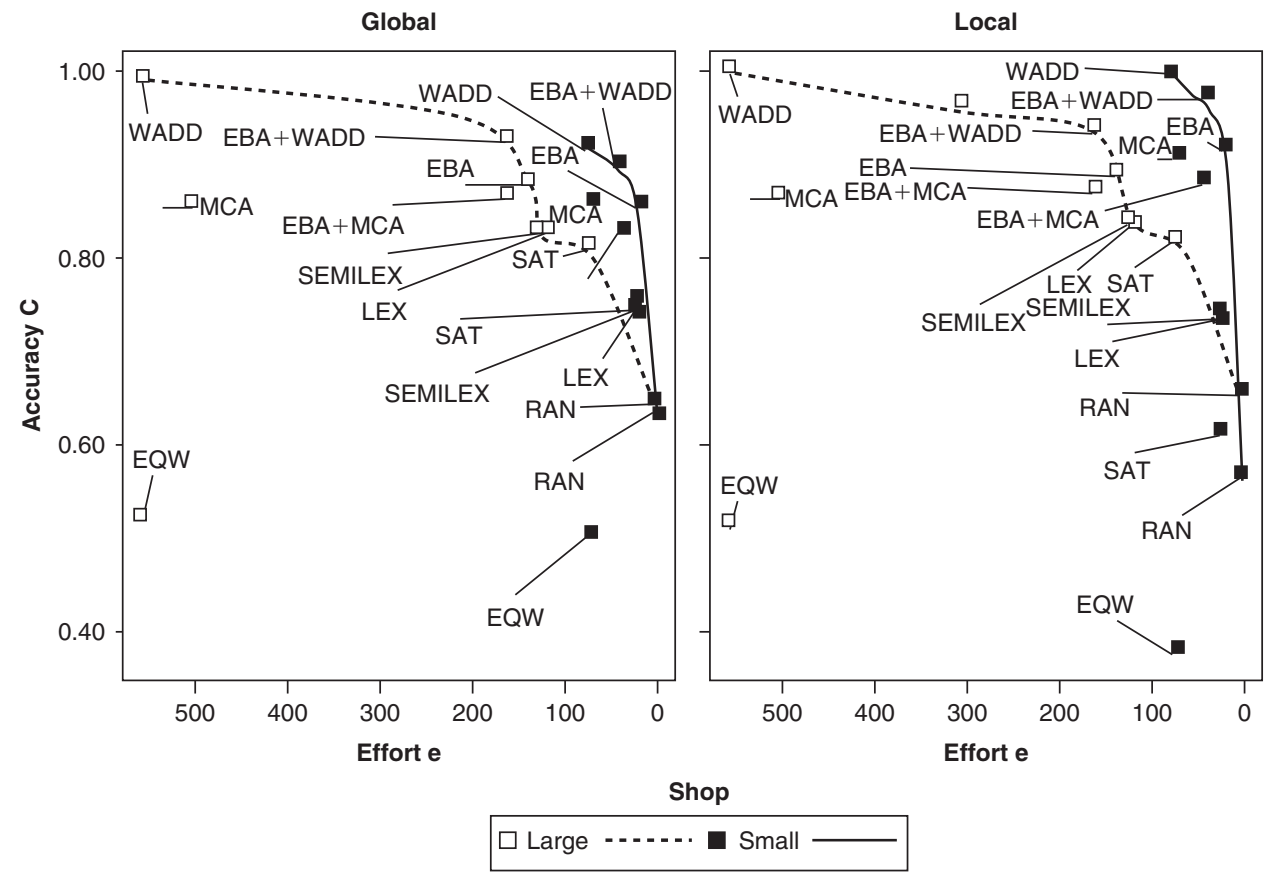

Figure 5b. Accuracy-effort frontier of the ten simulated strategies, for the pasta product category and two customer profiles (global and local). 


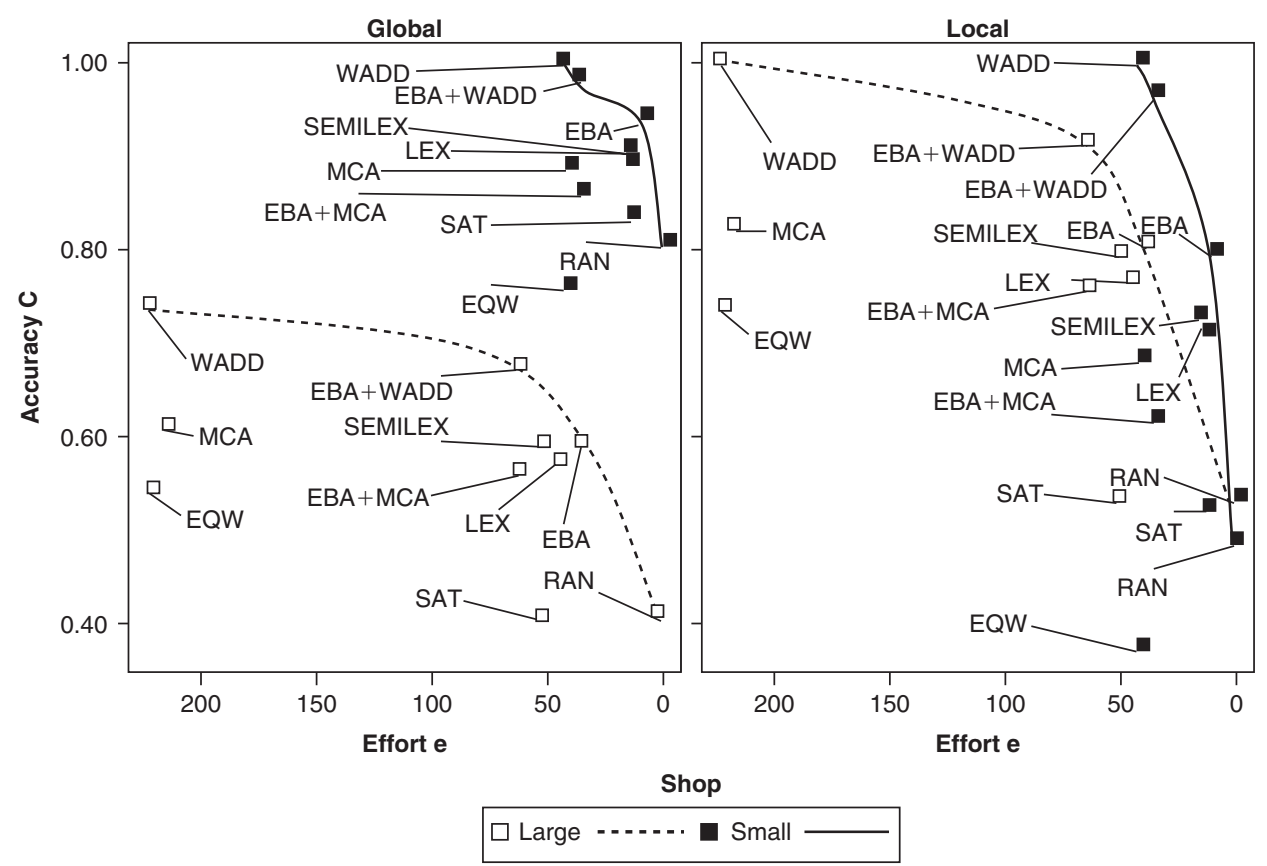

Figure 5c. Accuracy-effort frontier of the ten simulated strategies, for the margarine product category and two customer profiles (global and local).

for global and local in Figures 5a-c, except for global/yogurt, Figure 5a, left). Relatedly, the discrepancy in effort between compensatory (e.g., $W A D D$ ) and non-compensatory strategies (e.g., $S A T$ ) in the large store is vast relative to the parallel discrepancy in the small store.

A second point to note is that small stores might be an attractive shopping experience even for pickier customers with Jane Fuzzle's maximizing aspirationsif they are choosing a product from a typically small category, such as margarine. For this product category, choosing with any strategy from the small store leads to higher accuracy than choosing from the large store (Figure 5c, left graph), even for the picky consumer profile. For larger product categories, such as pasta, strategies in the small store achieve choices comparably accurate to those in the large store (Figure 5b, left graph). It is only when choosing from very large product categories, like yogurt, that the lesser effort of shopping in the small store exacts the price of less accurate choices (Figure 5a, left graph) for picky consumers. To sum up, even for maximizing consumers, the extent to which a small store will result in less accuracy depends on how complex the product line is from which one is choosing.

A last point to note is that in eight of 12 tests ( 3 categories $\times 2$ stores $\times 2$ preference structures), the non-compensatory elimination by aspect strategy is the best pure strategy, next to the weighted additive strategy (which defines the most accurate performance).

To conclude: Large assortments from the marketplace typically require-not surprisingly - substantially more effort to arrive at a choice, regardless of the strategy used and the customer's aspirations and preferences. Turning to accuracy, we find that if the customer's goal is to get the "super-duper" product, 
chances are that the larger store has it. Yet this result seems to depend on the length of the product line. For naturally small product lines (such as margarine), the small store turned out to offer the overall best product (Figure 5c, left graph), even for a customer whose goal is to get the best product across both stores. The small store enables customers with more modest aspirations to reach this goal using much less effort relative to the large store.

\section{GENERAL DISCUSSION}

Although considered crucially important, size is just one of the assortment properties that can affect consumer choices and perceptions. Next to size, the assortments' entropy and density have an impact on the ease with which people arrive at choices and the accuracy they achieve. Until now, properties such as size and entropy have been manipulated orthogonally in experiments and simulation studies. Brunswik (1955) referred to this predominant experimental approach as systematic design, and emphasized its risks. In his view, systematic design and its policy of isolating and controlling selected variables destroy the naturally existing causal texture of the environment to which the decision maker has adapted. The experimental stimuli presented to participants or used in simulations "are based on idealized black-white dramatization of the world, somewhat in a Hollywood style" (Brunswik, 1943, p. 261). Therefore, the generalizability of findings will be limited, unless stimuli are representative of a defined population of stimuli (for details see Dhami, Hertwig, \& Hoffrage, 2004).

To find out how the actual market presents large and small assortments to customers, and to understand how the statistical structure of small and large assortments, respectively, may contribute to the tyranny of choice phenomenon, we analyzed two representative German stores, both parts of successful supermarket chains and typical destinations of German shoppers. One chain is renowned for its explicit philosophy of offering little choice; in comparison, the other chain offers lots of choice. In simulations, Lurie (2004) observed that large assortments decrease decision quality relative to small assortments. In contrast, high-entropy assortments increase decision quality relative to low-entropy assortments.

Our ecological analysis of the assortments in the two supermarkets revealed that larger assortments tend to have higher density and higher entropy relative to smaller assortments. On the basis of these real-world assortments, we then asked the question of how ten different choice strategies, varying in the level of accuracy they promise and the effort they require, operate in them. We found that these strategies typically require substantially more effort to arrive at a choice from large, dense, and high-entropy assortments in the marketplace, relative to small, less dense, and lower-entropy assortments. How accurate people's choices are in these assortments depends on their aspiration level (Simon, 1983). If only the best is good enough, then, on average, they need to bite the bullet and invest the effort of scouting out the large assortment, at least when choosing a product from large lines. When choosing a product from smaller lines (e.g., margarine) or if the best in the local store is good enough, this aspiration can be achieved using substantially less effort relative to that required for reaching high accuracy in the large store.

Our simulations of real-world assortments further showed that higher choice accuracy in these naturalistic assortments emerged with more options. We can 
then return to the original question of the net effect of high entropy and large size on choice quality and suggest that the positive effect of high entropy on choice quality more than compensates for the negative effect due to the large size.

\section{How Something for Everyone Can Be Tyrannical}

Making choices takes time, thought, and effort. Therefore, the plethora of choices that the prodigious abundance in goods and service offers can carry a substantial price: People may choose not to participate, not to make a purchase, not to consume. Several attempts have been made to explain this too-much-choice effect (Reutskaja \& Hogarth, 2009; Scheibehenne, Greifeneder, \& Todd, 2009; White \& Hoffrage, 2009). Our contribution to these explanations is that sheer size is not the only culprit. The marketplace appears to evolve assortments in which size colludes with density and entropy. Specifically, we found a pattern in the structure of marketplace assortments that was, to the best of our knowledge, obscured by the practice of orthogonally manipulating properties such as size, density, and entropy of assortments. In reality, small and large real-world assortments tend to differ on more than just size. Large assortments tend to be denser and tend to have higher entropy than small assortments. In other words, entering a store that offers something for everyone means encountering a highdensity and high-entropy environment. Choosing a small store, one is more likely to enter the world of low-density and low-entropy environments. This finding is aligned with recent work (Kamenica, 2006), which proves that small assortments are structurally different from, and more informative than, large assortments. Given the reasonable assumption that assortments are constructed to contain popular products, and popularity is bound to decrease the more products are on offer, an uninformed consumer will find it more beneficial to choose from a small assortment of a few more popular products than from many less popular products. From this result one can view the marketplace has having some inner "wisdom" from which consumers can extract useful information. This view is certainly aligned with our finding that small assortments containing products that are more dissimilar from one another (i.e., are positioned to attract different segments of the market) make it easier for uninformed consumers to discriminate.

Further, our analyses suggest that the tyranny of too much choice experienced by customers standing in front of large assortments (Schwartz, 2000; Iyengar \& Lepper, 2000) can at least partly be attributed to factors other than size alone, namely large density and high entropy. The fact that many options are difficult to process could at least partly be caused or exacerbated by the fact that large assortments tend (1) to crowd the attribute space, making the interproduct distances smaller, and (2) to introduce many attribute levels (one component of entropy), thus making the information structure complex.

\section{How the Tyranny of Choice Can Be Attenuated}

Our findings have implications for customers as well as retailers and marketing experts. Schwartz et al. (2002) found that maximizers-those who express high values in a desire to maximize-are more prone to be unhappy, less optimistic, and have lower life satisfaction than satisficers. They also appear to be less satisfied with their consumer decisions than satisficers. The current analyses suggest reasons why maximizers may get the short end of the stick. First, 
if somebody is content with selecting the best product in a small choice set, he or she can do that using much less cognitive effort and time, relative to selecting the best product in a large set (Figure 5a-c, right graphs: local customer profile). Second, the intuition that the larger store will certainly offer the overall best product can be wrong. In the three product categories we analyzed, we found that the smaller store offered the best product in one of the three categories (margarine; Figure 5c, left graph). In other words, if a maximizer consistently prefers the large store, he or she may do better on average, but at a price in terms of cognitive effort and opportunity costs.

Our results also substantiate the concern voiced by some marketing practitioners (Ries \& Trout, 2001) that over-differentiation and too-long line extensions can be a trap. In adding a novel model or brand to a product line, retailers and marketing experts need to consider not just the consequences due to increasing size but also how new products alter the structure of the assortment, making it, for instance, more dense and increasing entropy. Until now, marketing researchers have mostly reduced information overload by offering fewer products. Broniarczyk, Hoyer, and McAlister (1998), for instance, demonstrated that reducing SKUs does not decrease customers' perception of variety. On the contrary, a $25 \%$ reduction in SKUs can even increase variety perception. In the same studies, customers reported having an easier time shopping when SKUs were decreased. Giving less choice to customers not only decreases costs of stock keeping, but can also increase sales (Boatwright \& Nunes, 2001) and market share (Draganska \& Jain, 2006; but for a different view, see Oppewal \& Koelemeijer, 2005). Our results suggest that rearranging products or removing selected products so as to reduce large assortments' density (i.e., larger interattribute distances) and entropy (i.e., fewer attribute levels) may be another route to reduce information overload. Or, if a store or manufacturer is committed to offering a large assortment, then density and entropy could inform the process of building up the assortment. Our study of the marketplace, for instance, has revealed that a few attributes such as price and brand appear to make up most of the product-category entropy and therefore are likely to crowd the consumer's mind. In creating large assortments, stores could aim to offer fewer brands and fewer price levels.

\section{Limitations and Future Research}

In studying how choice difficulty and choice accuracy are a function of size of assortments, density of attribute structure, and entropy, we went beyond the typical approach of orthogonally manipulating the variables of interest. In contrast, we analyzed 12 product lines in two real-world supermarkets, totaling 722 products and their, on average, 10 attribute values. Despite such an extensive sample, our analysis is, of course, limited by being confined to two stores. Two stores are not enough to generalize the results to all supermarket assortments. Yet both supermarkets are part of two popular chains in Germany, and, in fact, one chain exists beyond Germany, and consistently implements its philosophy of little choice. In other words, the small store we analyzed is characteristic of hundreds of similar stores across Europe. Having said that, we emphasize that future research could and should extend our analysis to other stores, other types of companies (e.g., online groceries; Boatwright \& Nunes, 2001, 2004; Borle et al., 2005; Zhang \& Krishna, 2007) and other product lines. 
A second limitation of our analysis lies in the measures we used. A quantity as seemingly simple as "size of an assortment" can be measured in multiple ways: Size can be defined in terms of the distinct products in a product line (e.g., the number of different yogurts in a store); alternatively, the size of an assortment could be measured in terms of the shelf space it occupies, or in terms of all "tokens" of one "type." An assortment that is small in terms of number of types (i.e., unique products) can be large in terms of number of tokens (i.e., instances of the types). The multitude of definitions also applies to the effort and density measures. We measured the ease of choice by a count of the number of attributes examined under each strategy to make a choice. This measure was in line with current research and related to notions of frugality. Alternative measures that take into account interproduct differences could be adopted by future research. Similarly, our density measure (the mean interproduct difference) does not take into account specifics of the distribution of the attribute values (e.g., skewness). Research in the tradition of range-frequency theory (cf. Parducci, 1965, 1995) has provided ample evidence that people's judgments are sensitive to skewness; moreover, many attribute value distributions are positively skewed (e.g., price). One key task for the future is thus to develop multiple measures for constructs such as assortment size and density of an assortment, and investigate their appropriateness in gauging people's perceptions and decision making.

\section{CONCLUSIONS}

Consumers are attracted to large assortments but appear confused and deterred by too much choice. Size per se, however, may not be the only obstacle to making a choice. By measuring and relating the size, density, and entropy of a dozen product categories in two general stores, we show that retail assortments that are large and aim to offer "something for everyone" also tend to crowd the attribute space with products that are close to other products. To the extent that this regularity generalizes to other large assortments in the marketplace, our results suggest that assortment planners may think of size, entropy, and density as somewhat independent variables that can be attuned. If so, choice from large assortments need not necessarily be tyrannical.

\section{REFERENCES}

Betrand, M., Karlan, D. S., Mullainathan, S., Shafir, E., \& Zinman, J. (2005). What's psychology worth: A field experiment in the consumer credit market. Working paper, National Bureau of Economic Research, Cambridge, MA.

Biggs, S. F., Bedard, J. C., Gaber, B. G., \& Linsmeier, T. J. (1985). The effects of task size and similarity on the decision behavior of bank loan officers. Management Science, 31, 970-987.

Boatwright, P., \& Nunes, J. C. (2001). Reducing assortment: An attribute-based approach. Journal of Marketing, 65, 50-63.

Boatwright, P., \& Nunes, J. C. (2004). Correction note for "Reducing assortment: An attributebased approach." Journal of Marketing, 68, iv.

Böckenholt, U., Albert, D., Aschenbrenner, M. K., \& Schmalhofer, F. (1991). The effects of attractiveness, dominance, and attribute differences on information acquisition in 
multi-attribute binary choice. Organizational Behavior and Human Decision Processes, 49, 258-281.

Borle, S., Boatwright, P., Kadane, J. B., Nunes, J. C., \& Shmueli, G. (2005). The effect of product assortment changes on customer retention. Marketing Science, 24, 616-622.

Botti, S., \& Iyengar, S. S. (2006). The dark side of choice: When choice impairs social welfare. Journal of Public Policy and Marketing, 25, 24-38.

Brandstätter, E., Gigerenzer, G., \& Hertwig, R. (2006). The priority heuristic: Making choices without trade-offs. Psychological Review, 113, 409-432.

Broniarczyk, S. M., Hoyer, W. D., \& McAlister, L. (1998). Consumers' perceptions of the assortment offered in a grocery category: The impact of item reduction. Journal of Marketing Research, 35, 166-176.

Brunswik, E. (1943). Organismic achievement and environmental probability. Psychological Review, 50, 255-272.

Brunswik, E. (1955). Representative design and probabilistic theory in a functional psychology. Psychological Review, 62, 193-217.

Chernev, A. (2003a). When more is less and less is more: The role of ideal point availability and assortment in consumer choice. Journal of Consumer Research, 30, 170-184.

Chernev, A. (2003b). Product assortment and individual decision processes. Journal of Personality and Social Psychology, 85, 151-162.

Coombs, C. H., \& Avrunin, G. S. (1977). Single-peaked functions and the theory of preference. Psychological Review, 84, 216-230.

Dhami, M. K., Hertwig, R., \& Hoffrage, U. (2004). The role of representative design in an ecological approach to cognition. Psychological Bulletin, 130, 959-988.

Dhar, R. (1996). The effect of decision strategy on deciding to defer choice. Journal of Behavioral Decision Making, 9, 265-281.

Dhar, R. (1997). Consumer preference for a no-choice option. Journal of Consumer Research, 24, 215-231.

Draganska, M., \& Jain, D. C. (2006). Consumer preferences and product-line pricing strategies: An empirical analysis. Marketing Science, 25, 164-174.

Fasolo, B., Carmeci, F., \& Misuraca, R. (2009). The effect of choice complexity on perception of time spent choosing: When choice takes longer, but feels shorter. Psychology \& Marketing, 26, 213-228.

Fisman, R., Iyengar, S. S., Kamenica, E., \& Simonson, I. (2006). Gender differences in mate selection: Evidence from a speed dating experiment. Quarterly Journal of Economics, 121, 673-697.

Garner, W. R. (1962). Uncertainty and structure as psychological concepts. New York: Wiley.

Hastie R., \& Dawes, R. M. (2001). Rational choice in an uncertain world. Thousand Oaks, CA: Sage.

Haynes, G. A. (2009). Testing the boundaries of the choice overload phenomenon: The effect of number of options and time pressure on decision difficulty and satisfaction. Psychology \& Marketing, 26, 204-212.

Hoch, S. J., Bradlow, E. T., \& Wansink, B. (1999). The variety of an assortment. Marketing Science, 18, 527-546.

Hoch, S. J., Bradlow, E. T., \& Wansink, B. (2002). Rejoinder to "The variety of an assortment: An extension to the attribute-based approach." Marketing Science, 21, 342-346.

Iyengar, S. S., \& Kamenica, E. (2006). Choice overload and simplicity seeking. Working paper, University of Chicago, Chicago, IL.

Iyengar, S. S., \& Lepper, M. R. (2000). When choice is demotivating: Can one desire too much of a good thing? Journal of Personality and Social Psychology, 79, 995-1006.

Iyengar, S. S., Jiang, W., \& Huberman, G. (2004). How much choice is too much? Determinants of individual contributions in $401(\mathrm{k})$ retirement plans. In O. S. Mitchell \& S. P. Utkus (Eds.), Pension design and structure: New lessons from behavioral finance (pp. 83-96). Oxford: Oxford University Press.

Jacoby, J., Speller, D. E., \& Kohn, C. A. (1974). Brand choice behavior as a function of information load. Journal of Marketing Research, 11, 63-69. 
Jessup, R. K., Veinott, E. S., Todd, P. M., \& Busemeyer, J. R. (2009). Leaving the store empty-handed: Testing explanations for the too-much-choice effect using decision field theory. Psychology \& Marketing, 25, 299-320.

Johnson, E. J., \& Payne, J. W. (1985). Effort and accuracy in choice. Management Science, 31, 395-414.

Kahn, B. E., \& Wansink, B. (2004). The impact of assortment structure on perceived variety and consumption quantity. Journal of Consumer Research, 30, 519-533.

Kamenica, E. (2006). Contextual inference in markets: On the informational content of product lines. Working paper, University of Chicago, Chicago, IL.

Keller, K. L., \& Staelin, R. (1987). Effects of quality and quantity of information on decision effectiveness. Journal of Consumer Research, 14, 200-213.

Lehmann, D. R. (1998). Customer reactions to variety: Too much of a good thing? Journal of the Academy of Marketing Science, 26, 62-65.

Lenton, A. P., Fasolo, B., \& Todd, P. M. (2008). “Shopping” for a mate: Expected vs. experienced preferences in online mate choice. IEEE Transactions on Professional Communication (Special Section: Darwinian perspectives on electronic communication), 51, 169-182.

Lichtenstein, S., \& Slovic, P. (2006). The construction of preference. Cambridge: Cambridge University Press.

Lurie, N. H. (2004). Decision making in information-rich environments: The role of information structure. Journal of Consumer Research, 30, 473-486.

McClelland, G. H. (1997). Optimal design in psychological research. Psychological Methods, 2, 3-19.

Oppewal, H., \& Koelemeijer, K. (2005). More choice is better: Effects of assortment size and composition on assortment evaluation. International Journal of Research in Marketing, 22, 45-60.

Parducci, A. (1965). Category judgment: A range-frequency theory. Psychological Review, 72, 407-418.

Parducci, A. (1995). Happiness, pleasure, and judgment: The contextual theory and its applications. Mahwah, NJ: Erlbaum.

Payne, J. W., Bettman, J. R., \& Johnson, E. J. (1988). Adaptive strategy selection in decision making. Journal of Experimental Psychology: Learning, Memory, and Cognition, 14, 534-552.

Payne, J. W., Bettman, J. R., \& Johnson, E. J. (1993). The adaptive decision maker. Cambridge: Cambridge University Press.

Reutskaja, E., \& Hogarth, R. M. (2009). Satisfaction in choice as a function of the number of alternatives: When "goods satiate." Psychology \& Marketing, 26, 197-203.

Ries, A., \& Trout, J. (2001). Positioning: The battle for your mind. New York: McGraw-Hill.

Scheibehenne, B., Greifeneder, R., \& Todd, P. M. (2009). What moderates the too-muchchoice effect? Psychology \& Marketing, 26, 229-253.

Schwartz, B. (2000). Self-determination: The tyranny of freedom. American Psychologist, $55,79-88$.

Schwartz, B. (2004). The paradox of choice. New York: Ecco.

Schwartz, B., Ward, A., Monterosso, J., Lyubomirsky, S., White, K., \& Lehman, D. R. (2002). Maximizing versus satisficing: Happiness is a matter of choice. Journal of Personality and Social Psychology, 83, 1178-1197.

Scott, W. A. (1969). Structure of natural cognitions. Journal of Personality and Social Psychology, 12, 261-278.

Shah, A. M., \& Wolford, G. (2007). Buying behavior as a function of parametric variation of number of choices. Psychological Science, 18, 369-370.

Shannon, C. E., \& Weaver, W. (1949). The mathematical theory of communication. Urbana: University of Illinois Press.

Shugan, S. M. (1980). The cost of thinking. Journal of Consumer Research, 7, 99-111.

Shugan, S. M. (1989). Product assortment in a triopoly. Management Science, 35, 304-320.

Simon, H. A. (1983). Models of bounded rationality. Cambridge, MA: MIT Press. 
van Herpen, E., \& Pieters, R. (2002). The variety of an assortment: an extension to the attribute-based approach. Marketing Science, 21, 331-341.

von Winterfeldt, D., \& Edwards, W. (1986). Decision analysis and behavioral research. New York: Cambridge University Press.

White, C. M., \& Hoffrage, U. (2009). Testing the tyranny of too much choice against the allure of more choice. Psychology \& Marketing, 26, 280-298.

Zhang, J., \& Krishna, A. (2007). Brand-level effects of stockkeeping unit reductions. Journal of Marketing Research, 44, 545-559.

Zinkhan, G. M., \& Braunsberger, K. (2004). The complexity of consumers' cognitive structures and its relevance to consumer behavior. Journal of Business Research, 57, $575-582$.

We gratefully acknowledge Simona Botti, Sheena Iyengar, Emir Kamenica, Laura Martignon, Erica van Herpen, Brian Wansink, the editors, and two anonymous reviewers for their helpful discussions and comments on earlier drafts. We also thank Laura Wiles for editing the manuscript, and the Jacobs Foundation for a grant to the second author.

Correspondence regarding this article should be sent to: Barbara Fasolo, Department of Management, London School of Economics and Political Sciences, London WC2A 2AE, U.K. (b.fasolo@lse.ac.uk). 